\title{
REVIEW
}

\section{Microbial community assembly in marine sediments}

\author{
Caitlin Petro* $^{* *}$, Piotr Starnawski ${ }^{* *}$, Andreas Schramm*, Kasper U. Kjeldsen \\ Section for Microbiology and Center for Geomicrobiology, Department of Bioscience, Aarhus University, \\ 8000 Aarhus C, Denmark
}

\begin{abstract}
Marine sediments are densely populated by diverse communities of archaea and bacteria, with intact cells detected kilometers below the seafloor. Analyses of microbial diversity in these unique environments have identified several dominant taxa that comprise a significant portion of the community in geographically and environmentally disparate locations. While the distributions of these populations are well documented, there is significantly less information describing the means by which such specialized communities assemble within the sediment column. Here, we review known patterns of subsurface microbial community composition and perform a meta-analysis of publicly available 16S rRNA gene datasets collected from 9 locations at depths from $1 \mathrm{~cm}$ to $>2 \mathrm{~km}$ below the surface. All data are discussed in relation to the 4 major processes of microbial community assembly: diversification, dispersal, selection, and drift. Microbial diversity in the subsurface decreases with depth on a global scale. The transition from the seafloor to the deep subsurface biosphere is marked by a filtering of populations from the surface that leaves only a subset of taxa to populate the deeper sediment zones, indicating that selection is a main mechanism of community assembly. The physiological underpinnings for the success of these persisting taxa are largely unknown, as the majority of them lack cultured representatives. Ecological explanations for the observed trends are presented, including the possible influence of energy depletion and the physiological basis of major taxonomic shifts.
\end{abstract}

KEY WORDS: Marine sediment $\cdot$ Bacteria $\cdot$ Archaea $\cdot$ Microbial diversity $\cdot 16 \mathrm{~S}$ rRNA

\section{INTRODUCTION}

Marine sediments cover more than two-thirds of the Earth's surface and harbor the largest reservoir of organic carbon on the planet (Hedges \& Keil 1995). Extensive surveys of subsurface microbial life have demonstrated the existence of a diverse community of bacteria and archaea, with cells identified as deep as $2.5 \mathrm{~km}$ below the sediment surface (Schippers et al. 2005, Ciobanu et al. 2014, Inagaki et al. 2015). Baas Becking's long-standing hypothesis that 'everything is everywhere, but the environment selects' (Baas Becking 1934, p. 15; translation according to

\footnotetext{
*Corresponding author: andreas.schramm@bios.au.dk
}

** These authors contributed equally to this work de Wit \& Bouvier 2006) garners new relevance when examining the microbial community composition of these unique habitats. The water column acts as a constant source of input to the sediment below, which must result in a nearly global deposition of planktonic populations with a cosmopolitan distribution (Giovannoni 1990, Morris et al. 2002, Gilbert et al. 2012). Despite this constant influx, molecular surveys have demonstrated a clear difference between planktonic and benthic communities, with significant changes in community composition occurring already at the seafloor (Zinger et al. 2011, Hamdan et al. 2013, Walsh et al. 2016a). This shift delineates benthic communities

() The authors 2017. Open Access under Creative Commons by Attribution Licence. Use, distribution and reproduction are unrestricted. Authors and original publication must be credited.

Publisher: Inter-Research · www.int-res.com 
from the marine habitat as a whole, suggesting that unique and decisive processes are responsible for driving the community composition of sediment environments. Such broad changes continue into the subseafloor environment, as demonstrated by a reduction in species diversity with depth and a vertical stratification of dominant populations, the majority of which have no cultivated representatives (Sørensen \& Teske 2006, Orcutt et al. 2011, Parkes et al. 2014, Walsh et al. 2016a,b, Starnawski et al. 2017). While the distributions of these populations are well documented, there is less information describing the parameters responsible for shaping subsurface communities. Links between environmental parameters and community composition have been proposed (Inagaki et al. 2006, Hewson et al. 2007, Jorgensen et al. 2012); however, these appear to be overshadowed by a global distribution of dominant populations which occurs independently of environmental conditions (Orcutt et al. 2011, Parkes et al. 2014). What factors are responsible for driving community dynamics within the isolated subsurface biosphere? Are populations filtered out from the sediment surface, or does evolution have a hand in constantly shaping a uniquely adapted subsurface community? Our understanding of the relative influence of these and other processes in the subsurface environment hinges on a dissection of community assembly, which is defined as the means by which the species composition of a community is determined (Mittelbach \& Schemske 2015).

Community assembly is governed by a myriad of overlapping processes. In an attempt to disentangle these processes and reduce the mounting complexity associated with the study of community ecology, Vellend proposed a conceptual synthesis that centers on 4 major assembly mechanisms: (1) dispersal, i.e. the movement of cells across space; (2) speciation (or diversification), i.e. the generation of genetic variation; (3) drift, i.e. random changes in community composition across time; and (4) selection, i.e. the change in community structure due to fitness differences among community members (Vellend 2010, Nemergut et al. 2013). This framework has since been evaluated for microbial systems, providing a unified lens through which microbial community assembly patterns can be investigated (Nemergut et al. 2013). While none of these processes act in isolation, the relative importance of each may vary among different systems (Vellend 2010, Stegen et al. 2013). To date, these processes have largely been evaluated in aquifer communities (Stegen et al. 2012, 2013), leaving us without a comprehensive framework describing community assembly in the marine subsurface.
The objective of this review is to explore the topic of microbial community assembly in relation to subsurface marine sediments, integrating our current understanding of the 4 major assembly processes with our knowledge of subsurface environmental conditions and depth distributions of microbial taxa. In addition, we present a meta-analysis of 16S rRNA gene sequence diversity, collected from 9 globally distributed sites at depths ranging from $1 \mathrm{~cm}$ to $>2 \mathrm{~km}$ below the seafloor and discuss these data in relation to the 4 major processes of microbial community assembly: diversification, dispersal, selection, and drift.

\section{Sediment environment}

The vertical structure of the sediment column consists of newly deposited material on the surface that increases in age with depth. Cells that are deposited from the planktonic realm or that populate the surficial environment become buried over time, gradually separating them from the sediment surface and exposing them to a successive change in environmental conditions. One of the most pronounced of these changes is energy depletion-a process resulting from both the microbial oxidation of buried organic matter as well as its increasing recalcitrance with sediment depth and age (Middelburg 1989, Langerhuus et al. 2012, Lomstein et al. 2012). This decrease in energy availability is reflected in the cell-specific metabolic rates within the community, which drop by 2 to 3 orders of magnitude within the uppermost meters of the sediment column (Holmkvist et al. 2011, Røy et al. 2012). This pattern is mirrored by a steady regression of microbial cell numbers with depth, a trend which can be correlated to both the age of the sediment as well as the availability of organic matter (Kallmeyer et al. 2012, Parkes et al. 2014, Jørgensen \& Marshall 2016). The relationship between community size and energy availability is believed to be the product of a basal power requirement (BPR), which refers to the minimum amount of energy required for basic repair and maintenance functions (Lever et al. 2015, Jørgensen \& Marshall 2016). Organic matter quality and quantity determine the energy flux available at a given sediment depth and age, and the BPR determines the theoretical upper limit of the community size that can be supported at this energy flux (Hoehler \& Jørgensen 2013, Kempes et al. 2017). Despite the strong energy limitations in the deep subsurface, amino acid racemization models suggest that vegetative cells must continually turn over their biomass during burial 
(Langerhuus et al. 2012, Lomstein et al. 2012). Active cells may, however, exist in a survival state, devoting their limited energy to the repair and synthesis of essential biomolecules rather than to cell division and growth (Langerhuus et al. 2012, Lomstein et al. 2012, Lever et al. 2015, Kempes et al. 2017).

Energy availability and community size can be correlated to rates of organic matter burial or to sedimentation rates (Parkes et al. 2014). Such rates can vary between sites and are usually dependent on productivity of the overlying water column, water depth, and the flux of clastic material and organic matter from land, with regions underlying coastal waters having higher rates of burial (Middelburg et al. 1993).

In addition to this pattern of energy depletion, the sediment column also exhibits a depth-associated geochemical zonation (Fig. 1) resulting from the thermodynamically driven succession of different electron acceptors in the sediment (Froehlich et al. 1979, Canfield et al. 1993, Thamdrup et al. 1994). Near the sediment surface, geochemical stratification is disrupted due to sediment reworking and bioirrigation caused by the construction and venting of macrofaunal burrows and tubes. These structures collectively increase the area of the sediment-water interface, allowing

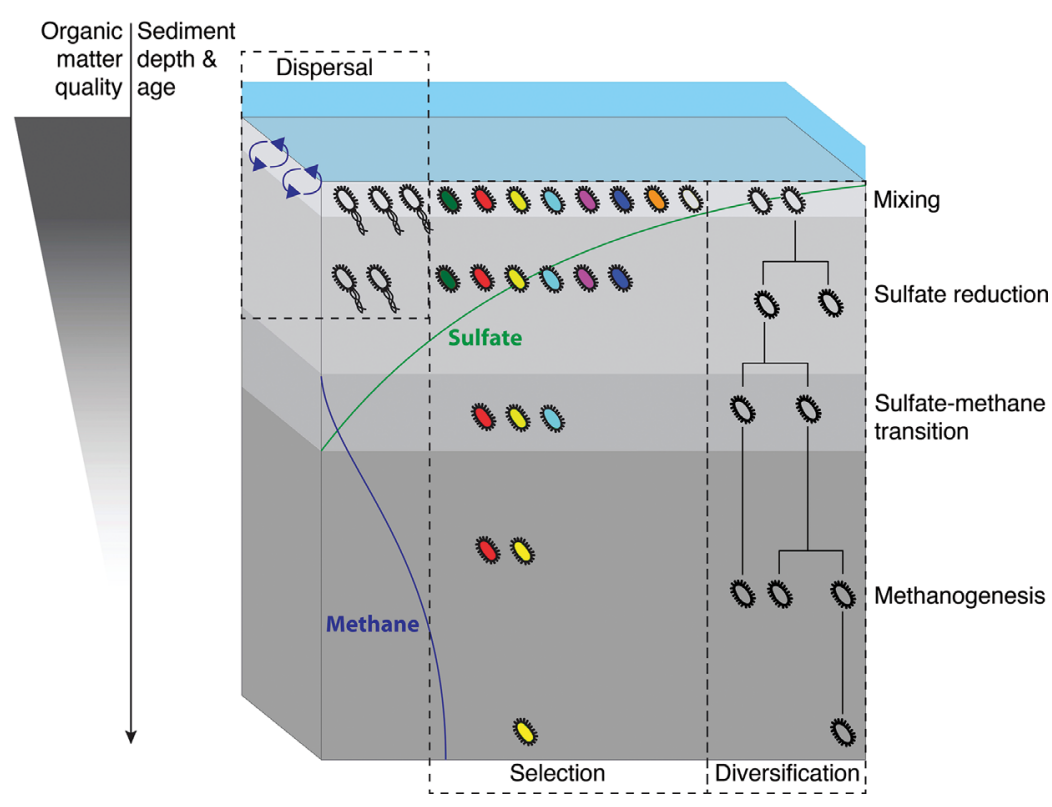

Fig. 1. Microbial community assembly processes in sediments. The 3 major community assembly processes (dispersal, selection, and diversification) and their respective consequence for the microbial community pattern are superimposed on a schematic drawing of the vertical biogeochemical zonation in marine sediments. Organic matter quality decreases with increasing sediment depth and age; the upper $10 \mathrm{~cm}$ are typically mixed by faunal activities (bioturbation, bioirrigation); sulfate is gradually depleted by microbial sulfate reduction, which is replaced by methanogenesis as a main terminal electron-accepting process at depth labile organic matter and dissolved metabolites to be transported deeper into the seafloor (Kristensen 2001, Reise 2002, Kristensen et al. 2012). Bioturbation processes reach a global average depth of $10 \pm 5 \mathrm{~cm}$ below the seafloor (cmbsf), creating a surficial zone marked by high geochemical heterogeneity and a downward extension of the oxidized surface environment (Boudreau 1998, Meysman et al. 2006). With little exception, microbial activity and community dynamics are highest within this region. This is due to both the mixing processes as well as the burrows themselves, which have been shown to harbor patches of stimulated microbial activity relative to the surrounding sediment (Reichardt 1988, Bertics \& Ziebis 2009). The transition out from below the bioturbation zone marks the beginning of the more stable subsurface, where energy is limited and diffusion takes over as the predominant mixing process (Jørgensen \& Marshall 2016). Sulfate reduction (SR) is the dominating remineralization process below this region, resulting in a sulfidic vertical expansion commonly referred to as the SR zone (Jørgensen 1982). Below the SR zone, the sulfate-dependent anaerobic oxidation of methane peaks in a narrow zone referred to as the sulfate-methane transition (SMT) zone, where a local maximum in SR rates is typically observed (Thomsen et al. 2001, Leloup et al. 2007). Sulfate is depleted at the SMT zone, at which point methanogenesis takes over as the predominant remineralization process (Holmkvist et al. 2011). The extension of these various zones is strongly influenced by the availability and input of organic matter into the sediment. In coastal areas, high biological productivity and increased rates of organic matter deposition lead to rapid oxygen depletion, thereby increasing the relative significance and extension of zones dedicated to anaerobic remineralization processes (D'Hondt et al. 2002). In low-productivity (e.g. gyre) areas, in contrast, organic matter deposition is extremely low, and oxygen can penetrate several meters into the sediment column (Røy et al. 2012).

\section{Microbial diversity in sediments}

Molecular analyses of microbial phylogenetic (16S rRNA) diversity in marine sediments have identified sev- 
eral key taxa that comprise a significant portion of the community in geographically and environmentally disparate locations (Biddle et al. 2006, Inagaki et al. 2006, Orcutt et al. 2011, Teske 2013, Parkes et al. 2014, Carr et al. 2015). Many of these taxonomic groups lack cultured representatives, leaving their physiological characteristics largely unknown. One of the most dominant phyla within subsurface sites is the Atribacteria (Dodsworth et al. 2013, Nobu et al. 2016), a newly classified phylum consisting of the candidate divisions OP9 (Hugenholtz et al. 1998) and JS1 (Webster et al. 2004). Other common bacterial phyla include the Proteobacteria, Chloroflexi, and Planctomycetes (Parkes et al. 2014). For Archaea, many sequences tend to cluster within uncultivated lineages belonging to several dominant phyla (Teske \& Sørensen 2008). Common lineages include Marine Group I (MG-I, DeLong 1992), now classified within the phylum Thaumarchaeota (Brochier-Armanet et al. 2008), as well as the Miscellaneous Crenarchaeotal Group (MCG, Inagaki et al. 2003), which has been recently separated into its own phylum, the Bathyarchaeota (Meng et al. 2014). Members of the Marine Benthic Group B/Deep Sea Archaeal Group (MBGB/DSAG, Vetriani et al. 1999, Inagaki et al. 2003) are also ubiquitous in subsurface environments. This lineage has recently been classified into its own separate candidate phylum, the Lokiarchaeota (Spang et al. 2015), within the Asgard superphylum (ZarembaNiedzwiedzka et al. 2017).

While universally prevalent, many of these taxa appear to predominate at different depths within the sediment column. Analyses of surface sediment are marked by a higher percentage of proteobacterial classes (Gamma-, Delta-, and Alphaproteobacteria) (Li et al. 2009, Quaiser et al. 2011, Zinger et al. 2011, Hamdan et al. 2013, Dyksma et al. 2016), while the subsurface is often dominated by sequences clustering within the Atribacteria and the 3 archaeal phyla mentioned in the previous paragraph (Teske 2006, 2013, Orcutt et al. 2011, Parkes et al. 2014). Analyses of the factors underlying these distribution patterns have proposed varying theories. One hypothesis is that geochemical zonation, or electron acceptor availability, may influence the vertical organization of subsurface prokaryotic populations (Durbin \& Teske 2012, Jorgensen et al. 2012). The community patterns that can be correlated to geochemical zonation are likely exhibited by functional groups of terminal oxidizers, which perform remineralization processes associated with specific zones (Loy et al. 2004, Leloup et al. 2007, 2009, Lever 2013). An example is the strong association of Deltaproteobacteria with SR in marine sediments. Because sulfate concentrations are generally highest in the surface layers, these populations tend to be most abundant in the surface and decrease with depth (Leloup et al. 2007, 2009, Blazejak \& Schippers 2011, Kawai et al. 2014). While such distributions are well documented, there are few data supporting the theory that geochemical zonation drives the composition of the total microbial community. This theory is also contradicted by the co-occurrence of microorganisms that occupy different metabolic niches, such as sulfate-reducing microorganisms and methanogens, throughout much of the sediment column (Leloup et al. 2007, Schippers et al. 2012). In addition, functional gene surveys and models of substrate uptake suggest that fermenters comprise the majority of subsurface populations (Lever 2013, Kirchman et al. 2014). Alternative analyses of microbial community composition have suggested that sediment depth and age, rather than geochemical zonation, may be a key driver of diversity (Walsh et al. 2016a, Starnawski et al. 2017). Such studies have identified a vertical succession of subsurface populations, resulting in communities from a given depth having similar composition regardless of geographic location or geochemical conditions. A recent analysis of this vertical succession found that sediment age and organic degradation rates exert primary control on changes in bacterial richness, with all properties declining with sediment depth (Walsh et al. 2016b).

\section{Meta-analysis of subsurface microbial diversity}

To produce a more comprehensive picture of microbial community composition throughout the sediment column, we performed a meta-analysis of available 16S rRNA datasets collected from a variety of habitats and depths (Table 1; Fig. 2). These depths span the length of the sediment column, providing a comprehensive overview of population changes that occur with the transition from the surface environment to the deep subsurface biosphere.

\section{MATERIALS AND METHODS}

The Sequence Read Archive (www.trace.ncbi.nlm. nih.gov/Traces/sra) was used to find all (as of January 2016) 16S rRNA gene datasets obtained from marine sediments. These were then screened for metadata, extracting only datasets with annotated sampling depths. The resulting datasets (Table 1) consisted of 292 sediment samples taken from 9 different geo- 
Table 1. Datasets used in the meta-analysis. Latitude, longitude, and depth were obtained with data from the Sequence Read Archive (SRA). Data can be accessed there using the SRA ID. Fragment length reflects the minimum sequence length considered in the analysis

\begin{tabular}{|lrcccccc}
\hline Location & Latitude & Longitude & $\begin{array}{c}\text { Depth } \\
\text { range }(\mathrm{m})\end{array}$ & $\begin{array}{c}\text { Fragment } \\
(\mathrm{bp})\end{array}$ & $\begin{array}{c}\text { No. of } \\
\text { samples }\end{array}$ & Reference \\
\hline Arctic Mid-Ocean Ridge & 73.57 & 8.16 & $0.16-3.1$ & 195 & 15 & Jorgensen et al. (2012) & SRP009131 \\
Canterbury Basin & -44.94 & 172.02 & $5.6-1922.27$ & 450 & 22 & Ciobanu et al. (2014) & ERP002102 \\
Caspian Sea & 39.75 & 50.48 & $0.02-0.34$ & 250 & 41 & Mahmoudi et al. (2015) & SRP047389 \\
China Sea off Taiwan & 22.39 & 119.90 & $0.5-4.5$ & 395 & 18 & Unpublished & SRP029906 \\
Gulf of Mexico & 28.88 & -90.43 & $0.01-0.09$ & 260 & 72 & Devereux et al. (2015) & SRP015731 \\
King George Island & -62.20 & -58.80 & $15-55$ & 500 & 16 & Unpublished & SRP017144 \\
Nankai Trough & 33.56 & 137.19 & $1-307$ & 400 & 12 & Reed et al. (2002) & DRP002370 \\
Pacific Margin & 41.18 & 142.20 & $1279.1-2458.8$ & 450 & 67 & Inagaki et al. (2015) & SRP052922 \\
Aarhus Bay & 56.15 & 10.32 & $0.089-10.55$ & 200 & 29 & Starnawski et al. (2017) SRP068282 \\
& & & & & & &
\end{tabular}

graphical locations (Fig. 2) at depths ranging from 2 $\mathrm{cm}$ to $2.5 \mathrm{~km}$ below the seafloor. The raw read files were downloaded from these datasets using sratoolkit version 2.5.4, supplied by the National Center for Biotechnology Information Web page. Each dataset was then quality screened using fastQC version 0.11 .4 software, where sequences shorter than $95 \%$ of the average length of the dataset were removed, resulting in 7387166 reads. Chimeric sequences were identified and removed by the UCHIME algorithm in de novo mode (Edgar et al. 2011). For each dataset, reads were clustered into operational taxonomic units (OTUs) based on a $97 \%$ sequence iden- tity cut-off using Usearch version 7.0.959 (Edgar 2013). OTUs were taxonomically classified using the classify.seqs function of mothur version 1.36 .1 software (Schloss et al. 2009), with the SSU Ref NR 99 Silva database (release 123) as a reference (Quast et al. 2013). With this database, $87 \%$ of the total number of reads across all datasets could be classified at the phylum level with default settings for the classify.seqs command. Unclassified reads were removed from further analysis. The resulting OTU-taxonomy tables were imported, combined, and analyzed in $\mathrm{R}$ version 3.2.0. In addition to subtracting control samples from the positive samples, as described by Inagaki et al.

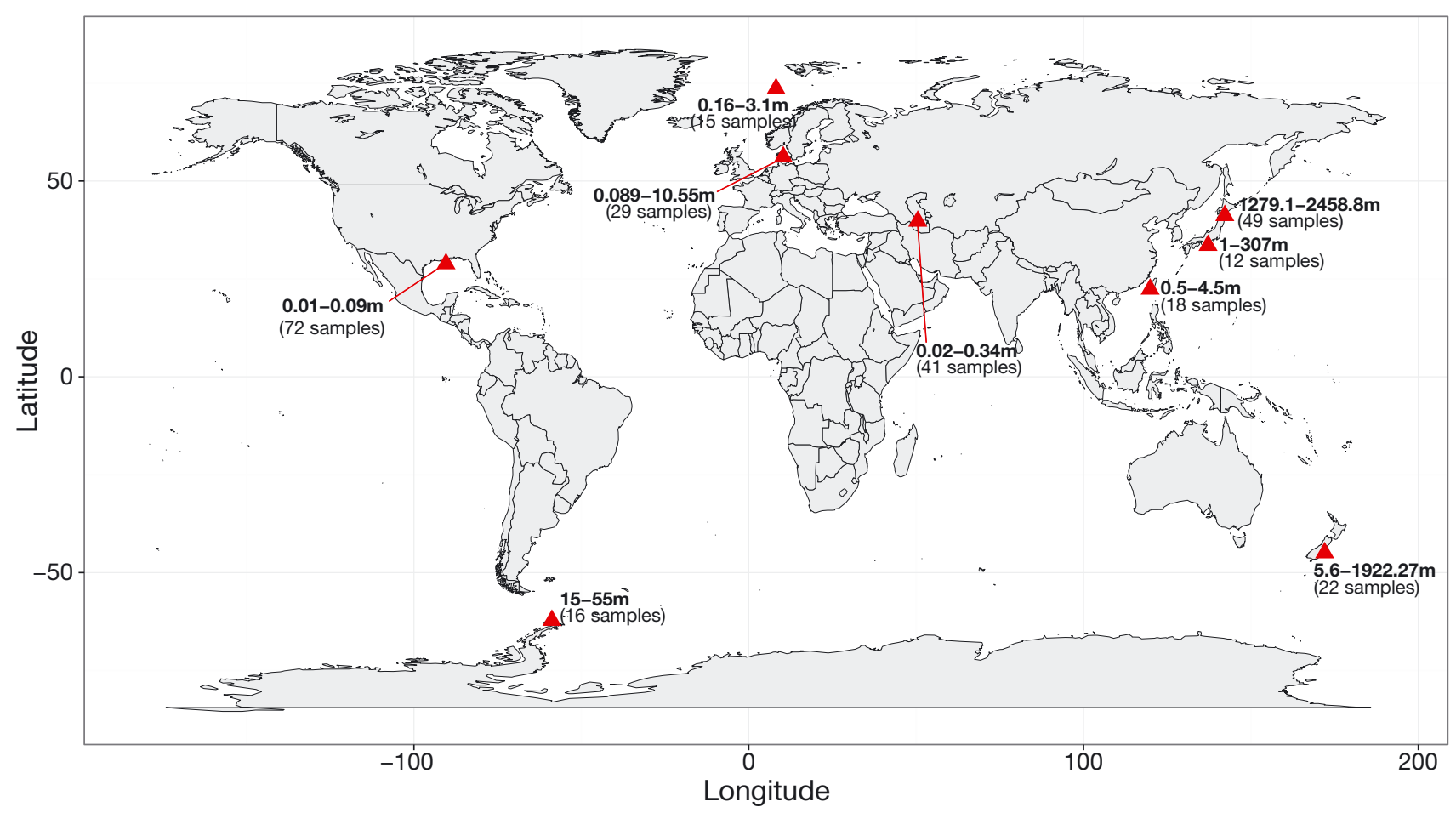

Fig. 2. Geographical location of sediment samples analyzed. Depth range (in meters below sediment surface) and total number of samples are shown for each study location 
(2015), and removing OTUs represented by a single sequence across a given dataset, all libraries were screened for common laboratory and extraction kit contaminants (Salter et al. 2014). OTUs that were found to be contaminants as classified at the genus level were then removed. For the Pacific Margin dataset (Table 1), OTU-level contaminants associated with drilling and present in negative control PCR reactions were also removed. The contaminant OTUs represented $<1 \%$ of the total reads for each dataset except for the Pacific Margin and the Caspian Sea datasets (Table 1), where the percentage was higher. The final dataset consisted of 6078606 reads. Shannon diversity and Chao 1 richness estimations were calculated on the resulting OTU tables using the vegan package (version 2.3.0).

To compare the OTU composition of communities across geographical locations, we aligned the qualityfiltered sequence reads from each of the 9 datasets against the SSU Ref NR 99 Silva database (release 123). We then combined datasets where sequence reads covered the same part of the 16S/18S rRNA gene and filtered out a $153 \mathrm{bp}$ long region spanned by the reads of the selected datasets for further analyses. The resulting dataset consisted of 792656 sequence reads representing 78 samples from 6 different geographical locations; 3 locations were excluded because of too-short read lengths or too-low read numbers after filtering. The sequences were clustered into OTUs as described in the previous paragraph, and the distribution of OTUs among samples was analyzed in $\mathrm{R}$ with the vegan package (version 2.4-2) by non-metric multidimensional scaling (NMDS) ordination based on a Wisconsin normalized Bray-Curtis dissimilarity matrix (see Fig. 7A). For 3 locations with samples covering a depth gradient of several meters, individual OTUs were traced across depth and the fraction of OTUs occurring in all depths (persisting OTUs) calculated for each depth (see Fig. 7B-D).

\section{RESULTS AND DISCUSSION}

The community composition within each depth interval was first examined by estimating alpha diversity, i.e. the diversity contained within a single habitat (Whittaker 1972). Analyses of diversity (Shannon index) and richness (Chao 1) indicate a drop in both parameters with depth (Fig. 3), with the highest values exhibited near the seafloor. The Shannon index estimates diversity, giving a higher weight per individual to rare species than to dominant species (Hill et al. 2003). Its decrease with depth is therefore in-
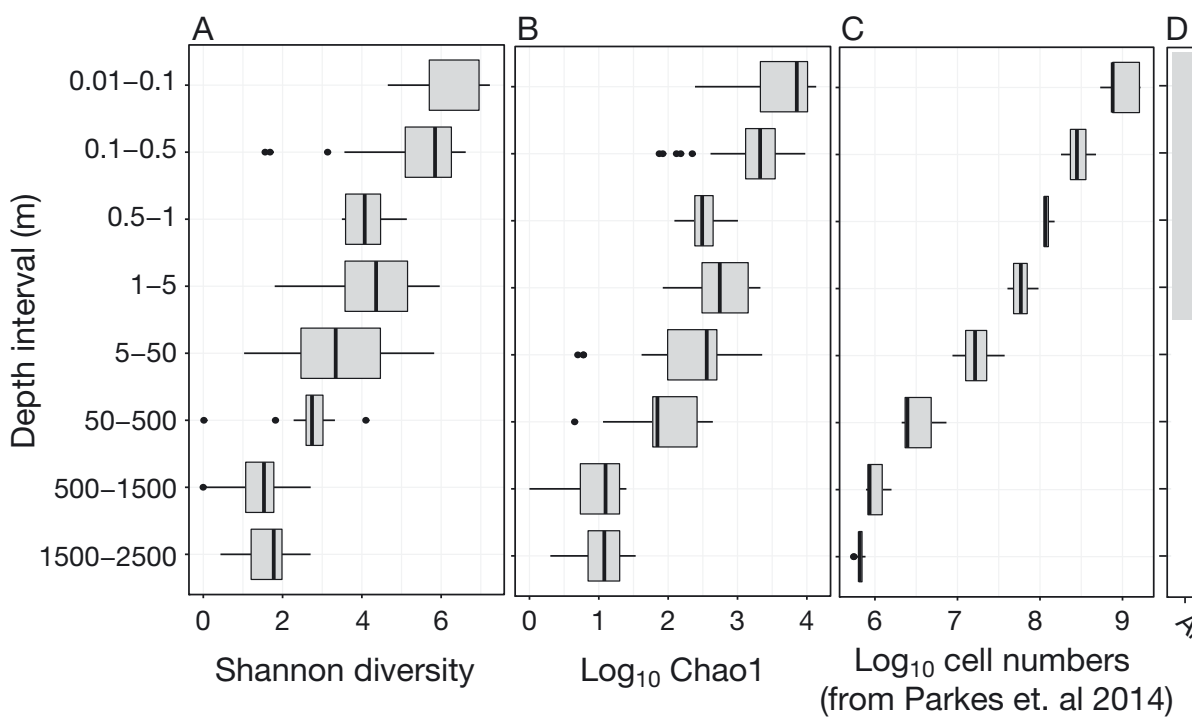

Fig. 3. Depth distribution of microbial diversity, species richness, and abundance in marine sediment. The common $y$-axis shows the depth intervals the dataset was divided into, with the first interval corresponding to the bioturbation zone. (A) Shannon diversity based on operational taxonomic unit clustering of 16S rRNA amplicon sequence datasets. (B) Chao1 richness estimates based on the same data as the Shannon index. (C) Cell numbers for the corresponding depths, estimated from the model proposed by Parkes et al. (2014). (D) Depth coverage of each dataset: grey bars represent the depth interval of the samples. In the box and whisker plots, the middle line represents the median value, and the horizontal lines represent the minimum and maximum values. The box stretches from the lower to the upper quartile, and dots show outliers ( $>1.5$ times the corresponding quartile). Gulf of Mexico data were excluded from diversity and richness calculations (A \& B), as they contain separate datasets for Bacteria and Archaea 


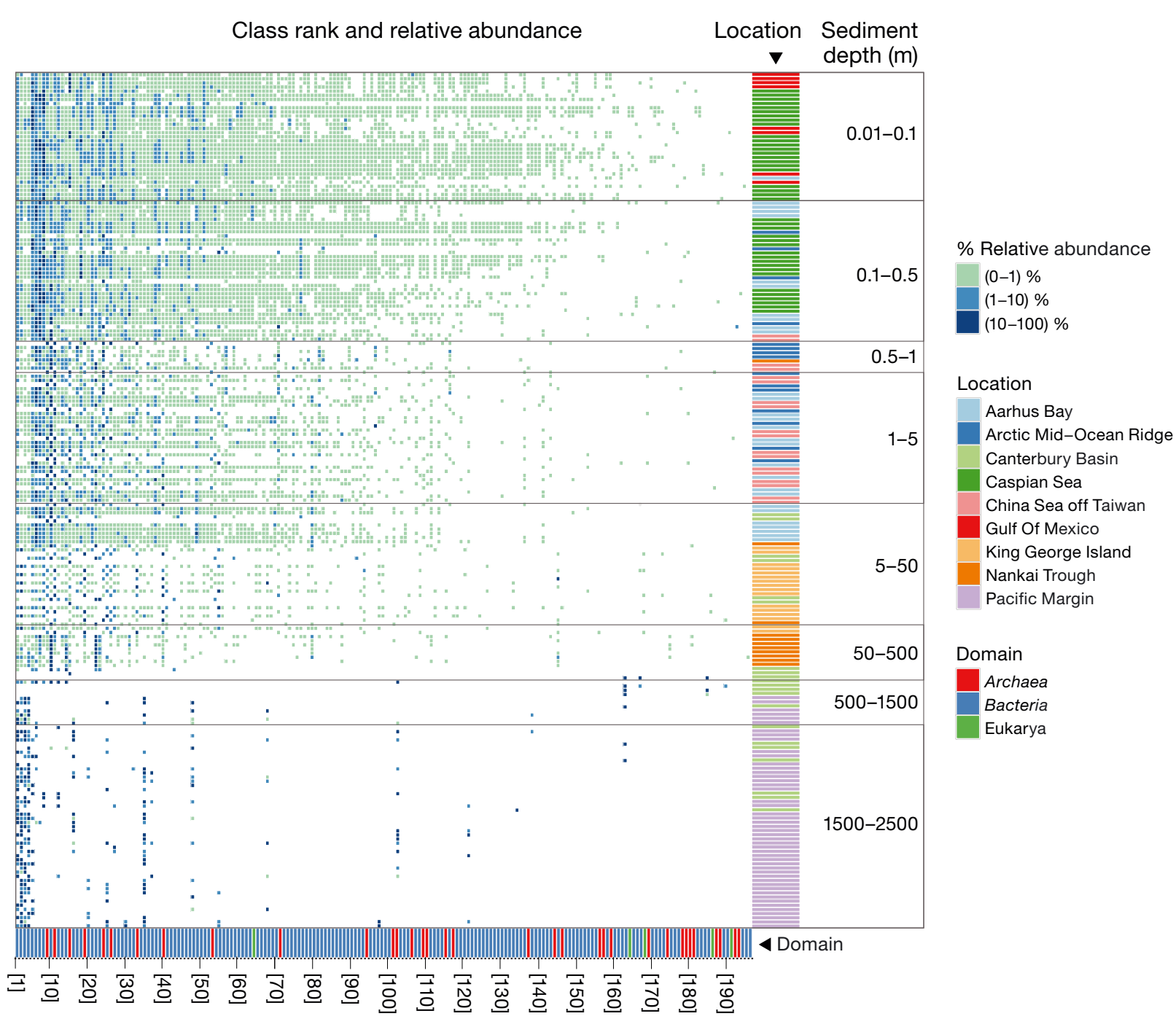

Fig. 4. Depth distribution of main taxonomic groups in marine sediments. The figure is based on analysis of 16S rRNA amplicon sequence libraries. The $y$-axis represents every single sample in the study arranged by depth, with the color scale indicating the origin of the sample. The $x$-axis displays the class-level taxonomic group arranged from most abundant on the left to least abundant on the right. Domain affiliation is indicated by color. The identities of the different numbered classes are provided in Table S1 in the Supplement at www.int-res.com/articles/suppl/a079p177_supp.pdf. Fill color intensity reflects the relative abundance interval of a given class at a given depth

dicative of a change from datasets containing many species in equal or low abundances in the surface (high index) to few dominant species in the deep subsurface (low index). The Chao 1 index provides an estimate of species richness, taking into account the number of rare species present within a sample (Hughes et al. 2001); it shows a decrease of the total number of species with depth. A similar pattern of decreasing diversity and richness was recently reported in a study of the equatorial Pacific Ocean and North Pacific Gyre (Walsh et al. 2016a). This study, which extended to a depth of $6 \mathrm{~m}$ below the seafloor (mbsf), found taxonomic richness estimates to be highest in the overlying water column and lowest in the deepest sediment samples taken. A more recent analysis found a similar pattern of decreasing richness with depth, with deeper extension into the sediment column (Walsh et al. 2016b). Here, we see the same trends on a global scale. The observed diversity and richness profiles resemble the drop in cell numbers with depth (Fig. 3), suggesting that processes constraining the community size also control community diversity. The diversity and richness estimates were supplemented by an overview of the predominant taxonomic changes from the surface environment to the deep biosphere (Fig. 4). This profile displays changes in the relative abundance of microbial classes with burial into the sediment column. The results are in- 
dicative of an environmental filtering process, with the disappearance of many microbial classes with increasing depth. To monitor the dynamics of the taxa that are most affected by this filtering, we identified the 20 most abundant taxonomic classes in the dataset and plotted changes in their relative abundances with depth (Fig. 5). Here, we see 2 main types of patterns: (1) initial high relative abundance populations that decrease with depth, e.g. Delta- and Gammaproteobacteria; and (2) initial low relative abundance populations that increase with depth, e.g. sporeformers (Bacilli and Clostridia), Atribacteria, Dehalococcoidia, and most of the Archaea. A very abrupt change in these patterns is observed for the 2 deepest intervals, which are based on samples from the Pacific Margin and Canterbury Basin. Below $300 \mathrm{~m}$ (Ciobanu et al. 2014) and $700 \mathrm{~m}$ (Inagaki et al. 2015), the analyzed sediments change in lithology from muddy to sandy or lignite coal, respectively. As a result, the 2 deepest intervals (Figs. 4 \& 5) represent unique environments compared to the rest of the sediment column. This is indicated by the exceptionally low diversity present within these samples, as well as the stark change in community composition relative to the overlying depths. In the study of Inagaki et al. (2015), the dominant community members were reported to resemble typical soil microbes, suggesting that the terrestrial origin of this sediment plays a role in its taxonomic composition. To further analyze changes in diversity with depth, 6 of the most abundant subsurface lineages were selected, and their respective OTU numbers per sample were counted and plotted across the entire depth profile. This analysis shows that the overall drop in community diversity (Fig. 3) is mirrored by a drop of diversity within individual lineages with depth (Fig. 6).

To examine similarities in OTU composition between geographic locations, we performed an additional analysis of beta diversity within the combined dataset. The resulting NMDS ordination shows that

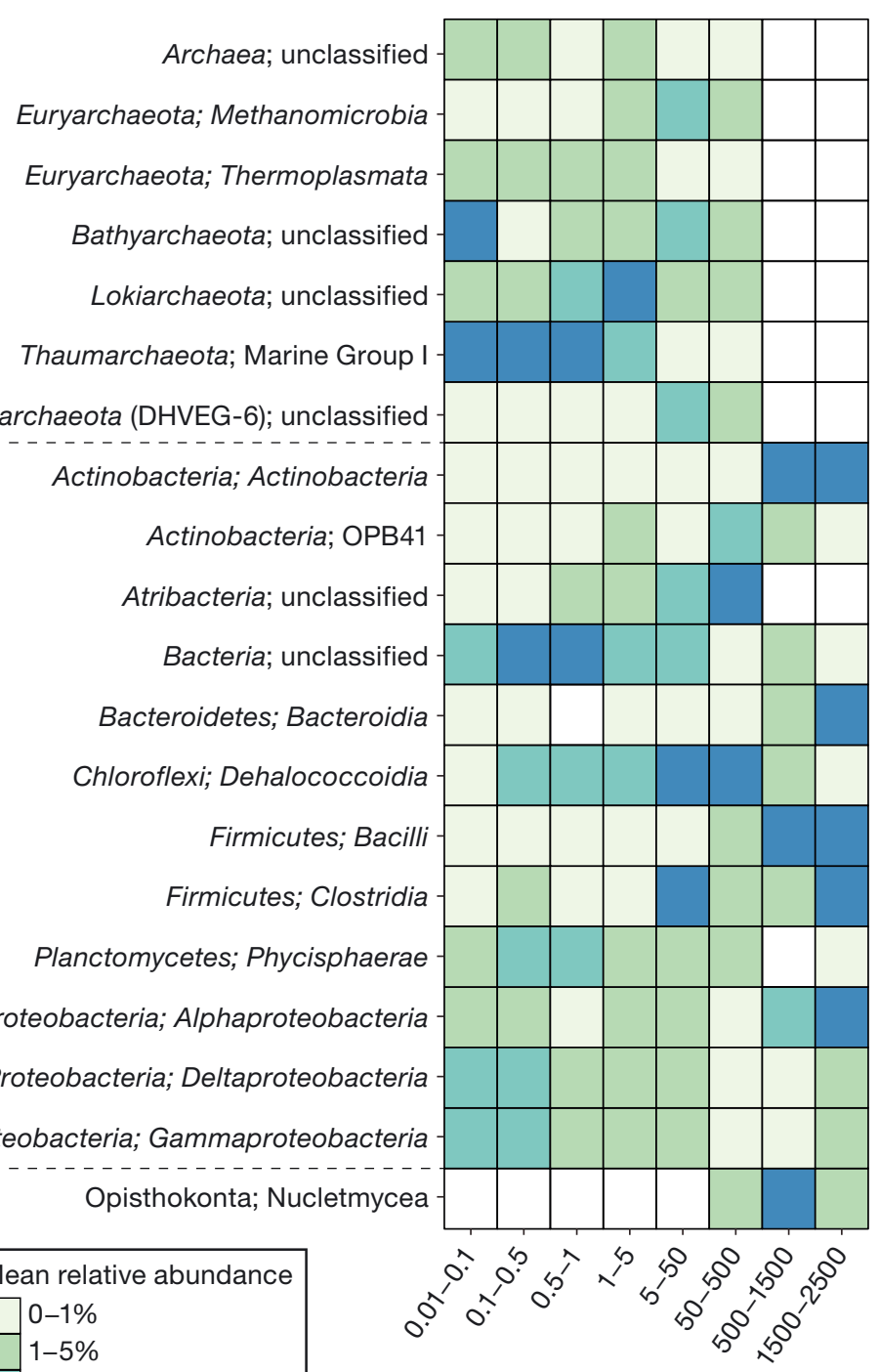

Sediment depth $(\mathrm{m})$

Fig. 5. Depth distribution of the top 20 most abundant taxonomic groups in marine sediments. The $y$-axis names the groups (class-level taxonomic resolution) of highest relative abundance in 16S rRNA amplicon sequence libraries from marine sediments, and the $x$-axis shows the sediment depth intervals. Fill color intensity reflects the mean relative abundance of sequence reads assigned to a group at a given depth

OTU composition varies broadly by site, indicating that each site contains a relatively distinct OTU community (Fig. 7A). While samples vary by site, the distribution of the total community is significantly correlated with depth $(\mathrm{p}<0.001)$, which suggests that increasing sediment depth drives a systematic change in the global microbial community. To examine this change more closely, we analyzed the distribution of OTUs across depth intervals from within 3 different sampling sites. Within each site, we traced OTUs across depth intervals, revealing a small subset of 

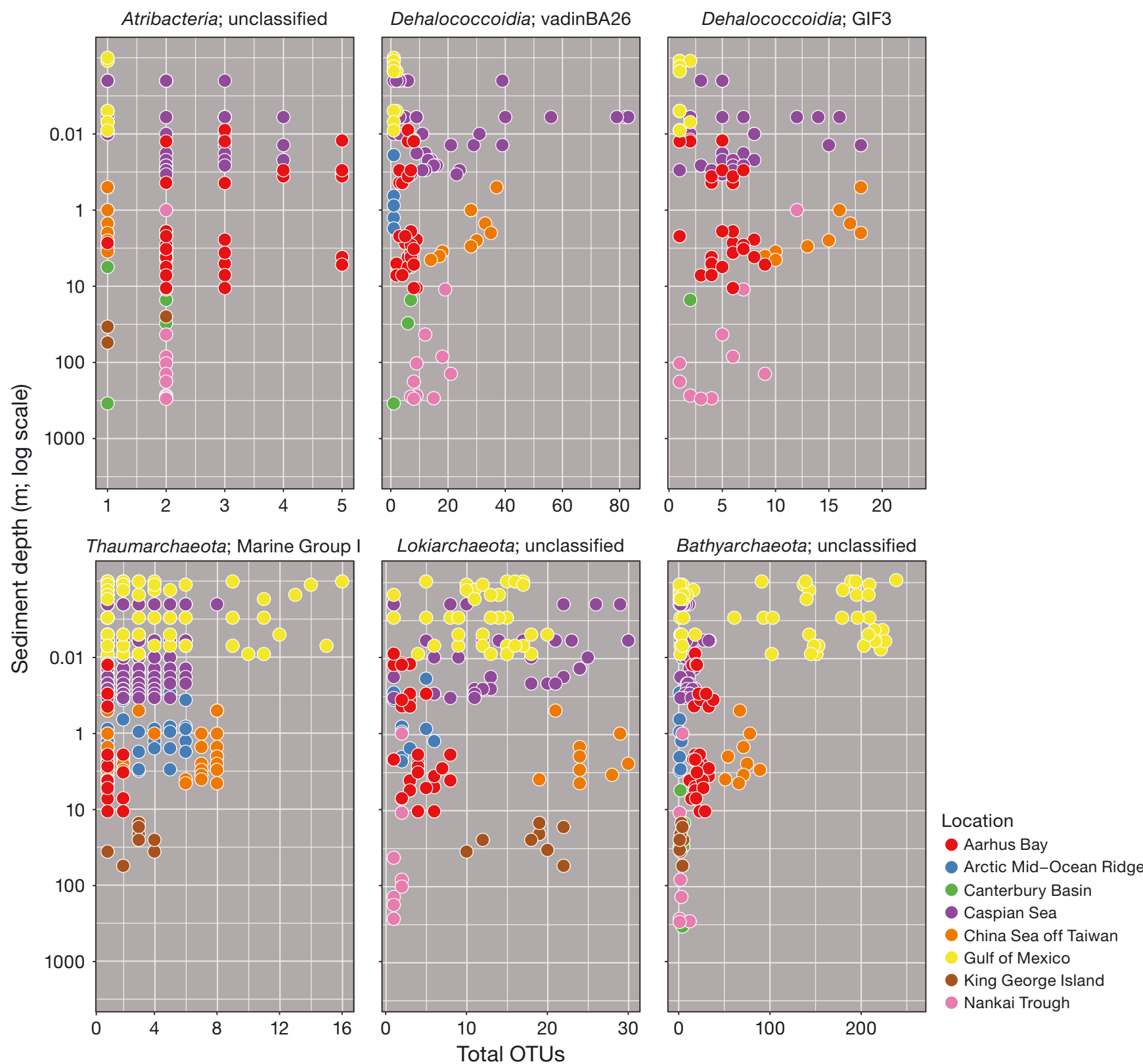

Fig. 6. Decrease of intra-lineage diversity with depth. For selected bacterial and archaeal lineages, the total number of operational taxonomic units (OTUs) classified to that lineage was counted for each depth. The $y$-axes are $\log _{10}$ depth scales, and the $x$-axes show the total count of OTUs detected for a given lineage. Coloring is based on sample location

OTUs that are present throughout all the sampled depths (Fig. 7B-D). These OTUs represent a small percentage of the total OTU richness in these sediments (4 to $18 \%$ ) but make up a significant proportion of the total microbial community (40 to $70 \%$ ). Closer examination of the taxonomic identity of these OTUs revealed that they belong to predominant subsurface lineages such as Atribacteria and Dehalococcoidia, which were among the most abundant persisting OTUs at all 3 sites.

\section{Microbial community assembly in sediments}

What processes are driving the broad community changes apparent in our meta-analysis? To better understand these patterns on a global scale, we will now review the 4 major processes of microbial community assembly: dispersal, diversification, drift, and selection (Fig. 1). By integrating our current knowledge of the marine subsurface environment, we seek to understand how these processes 


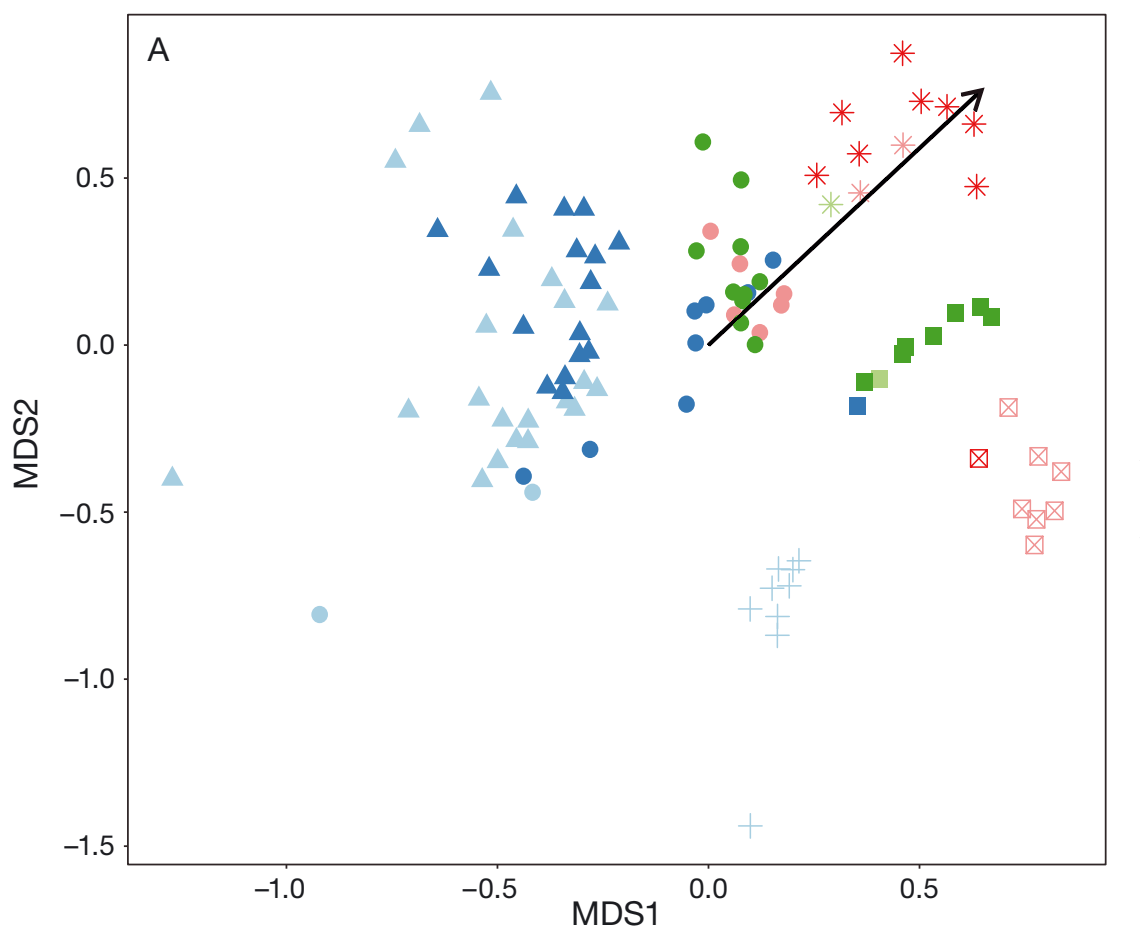

Depth interval $(\mathrm{m})$

$0.01-0.1$

$0.1-0.5$

$0.5-1$

$1-5$

$5-50$

$50-500$

Location

- Aarhus Bay

- Caspian Sea

China Sea off Taiwan + Gulf Of Mexico

$\bigotimes$ King George Island

* Nankai Trough
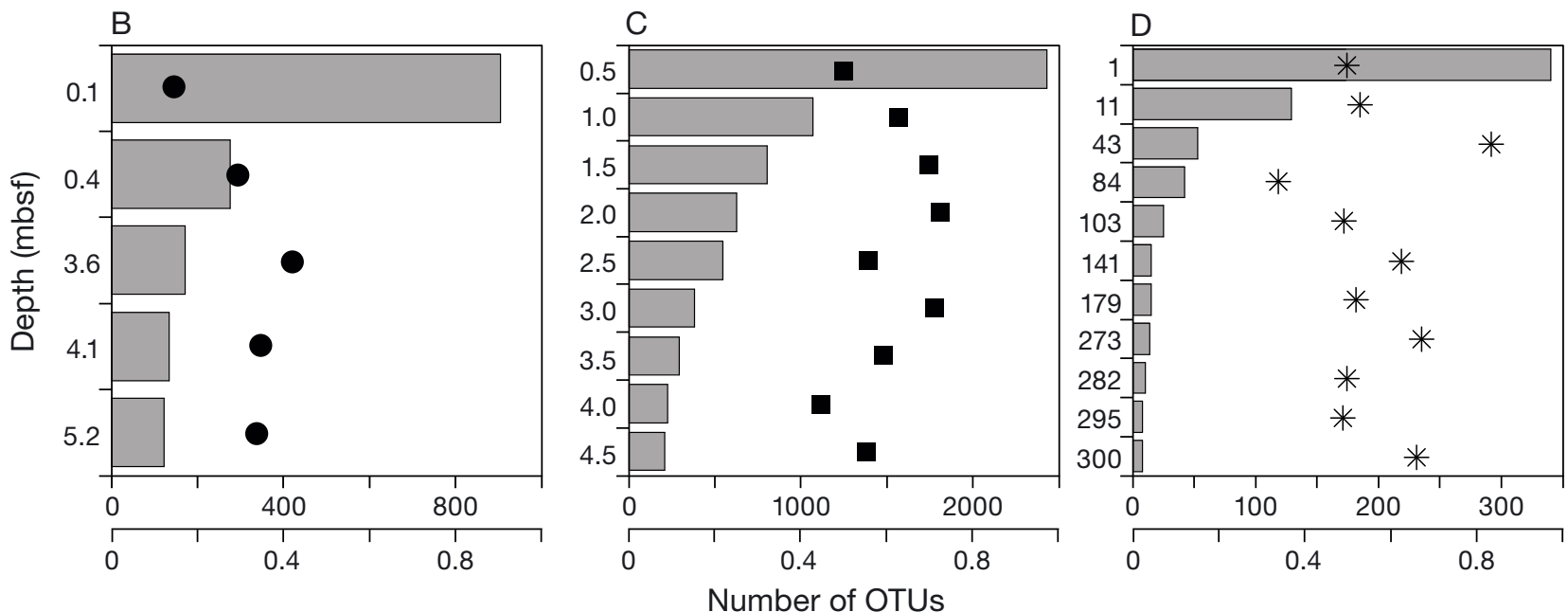

Relative abundance of OTUs persisting across all zones

Fig. 7. Change in operational taxonomic unit (OTU)-level microbial community composition with sediment depth. (A) Nonmetric multidimensional scaling ordination of sediment microbial communities from 6 locations (indicated by different symbols) based on their OTU composition. Sediment depth is indicated by the color gradient. The arrow indicates a significant correlation $(p<0.001)$ of the community composition with increasing depth. (B-D) Number and relative abundance of persisting OTUs across sediment depths for Aarhus Bay (B), China Sea (C), and Nankai Trough (D) samples. Grey bars show the abundance of 16S rRNA gene sequence OTUs persisting across different zones (OTU identities are provided in Table S2 in the Supplement at www.int-res.com/articles/suppl/a079p177_supp.pdf). Top: Total number of OTUs in the top zone. All other zones: number of OTUs from the top zone that persist at each of these zones. Bottom: number of OTUs persisting throughout all zones. The symbols depict the fraction of sequence reads in a given layer made of OTUs persisting across all zones. mbsf:

$\mathrm{m}$ below the seafloor

may operate within the sediment column and how they may influence the introduction and modification of microbial populations as they are buried over time.

\section{Dispersal}

Dispersal refers to the movement of organisms across space and can be both passive and active 
(Martiny et al. 2006, Nemergut et al. 2013). In the seabed, passive dispersal is largely restricted to the bioturbation zone, where macrofaunal burrowing constantly redistributes particulate matter and microbial cells (Meysman et al. 2006). Below this region, molecular diffusion takes over as the primary means of passive transport, limiting the potential for movement across large distances. To illustrate this limitation, Hoehler \& Jørgensen (2013) used the diffusion coefficient of micrometer-sized particles in porous sediments $\left(1 \times 10^{-9} \mathrm{~cm}^{2} \mathrm{~s}^{-1}\right.$; typo corrected from Hoehler \& Jørgensen 2013) to calculate the potential for microbial displacement by random Brownian motion. From this calculation, they determined that it would take roughly 1 million years for the average cell to traverse a vertical distance of only $6 \mathrm{~m}$. The structuring of the sediment matrix is likely to further limit this process, due to the tendency for subsurface cells to adhere to sediment particles (Meyer-Reil 1994, Lever et al. 2015). While the effects of such adhesion have not been directly measured in deeper sediments, quantification in the surface environment has shown that 40 to $90 \%$ (Fenchel 2008) or over $95 \%$ (Zäncker 2015) of the community is at least temporarily attached to the sediment matrix at any given time.

Active dispersal takes the form of motility, usually resulting from chemotactic attraction to low molecular weight organics or gradients of terminal electron acceptors (Fenchel 2002, 2008). In sediments, motile capabilities are largely paradoxical. They confer selective advantages in that they provide faster and directional access to energy sources within a highly energy-depleted environment. However, they do so at a high energetic cost, due to the need for maintenance and operation of specialized structures, such as the flagella (Taylor \& Stocker 2012, Hoehler \& Jørgensen 2013). Much like its passive counterpart, the potential for active dispersal is expected to peak within the bioturbation zone, due to the small-scale heterogeneity of the environment coupled with an increased availability of freshly deposited organic matter (Fenchel 2008). Within this more dynamic environment, it is feasible that motility serves as a means to avoid burial in locations with low sedimentation rates. This could allow motile bacteria to retain access to freshly deposited sources of organic matter over longer time scales. While there has been limited research on the motility of bacteria in deeper sediment layers, one could postulate that the low energy and homogeneity of the environment would not support a motile lifestyle (Lever et al. 2015). This is illustrated in one study in sandy sediments, which documents a drop in the percentage of motile cells from
$10 \%$ in the surface to $2-4 \%$ at $40 \mathrm{cmbsf}$ (Fenchel 2008). A more recent study in Aarhus Bay (Denmark) found similar results, indicating a drop in the motile fraction of the community from $1.8 \%$ at the seafloor to $0.2 \%$ at $50 \mathrm{~cm}$ depth (Zäncker et al. 2015). While examination of an alternate site found motile cells to comprise up to $20 \%$ of the total community at 40 cmbsf (Fenchel 2008), these numbers are likely to decline as energy availability diminishes. The potential for motility within the deep biosphere is particularly improbable, as the energy available there is incapable of driving flagellar propulsion (Hoehler \& Jørgensen 2013). This expectation of an immobilized deep biosphere is consistent with metagenomic surveys of deep subsurface sediments, which show that motility genes are rare and decrease with depth (Biddle et al. 2008). Collectively, these observations suggest that dispersal between sediment depths may play a limited role in driving vertical changes in subsurface microbial community composition. While passive and active dispersal are likely amplified within the surficial environment, they are unlikely to result in the long-distance displacement of populations within the sediment column.

\section{Diversification}

Diversification describes the generation of new genetic variation due to spontaneous mutations, gene loss and genome rearrangements, or horizontal gene transfer (HGT) (Prozorov 2001, Nemergut et al. 2013, Albalat \& Cañestro 2016). These processes hinge on community growth or a succession of multiple generations for genetic changes to settle in a population (Weller \& Wu 2015). Highly dynamic environments with higher growth rates are prone to higher rates of HGT and de novo mutations that introduce novel traits into populations and drive speciation events. Non-growing communities, in contrast, have little scope for adaptive change. Prior reviews on energy limitations in sediments have addressed the constraints on diversification faced by members of these slow-growing communities (Hoehler \& Jørgensen 2013, Lever et al. 2015, Jørgensen \& Marshall 2016). Based on results from a range of analytical approaches, these studies consistently produce strikingly low estimates of rates of turnover of microbial biomass, which serves as a proxy for the generation time of microbial populations. Such generation times are expected to increase steeply with depth, approaching tens to hundreds of years at only 1 mbsf. With such limited turnover, a buried community may go through as few 
as 11500 cumulative generations from when it is first buried below the bioturbation zone until it reaches a depth of 40 mbsf (Jørgensen \& Marshall 2016). These estimates provide very little basis for the introduction and propagation of beneficial mutations into subsurface populations, even over the geologic time scales by which sediments accumulate. Indeed, looking at the diversity changes within individual lineages (Fig. 6), there is no evidence of species-level diversification in sediments. The number of OTUs within a given lineage generally decreases with depth, indicating that new OTUs do not arise as populations are buried within the sediment column. Diversification could still act at genetic levels not reflected in 16S rRNA, thereby imparting changes in functional genes or physiological traits not discernible by the taxonomic data presented here. However, a recent study on genome evolution in the subsurface showed that nucleotide sequence diversity of dominant lineages was low and relatively stable across the length of the sediment column, suggesting that evolutionary changes are limited across the entirety of the genome (Starnawski et al. 2017). In theory, the rates of diversification could be amplified by different factors, such as the propensity for microorganisms to acquire genes from other organisms through HGT (Wiedenbeck \& Cohan 2011). Since viruses appear to be highly abundant in subsurface sediments, they could act to accelerate rates of HGT (Engelhardt et al. 2014, 2015). However, due to the apparent lack of longdistance dispersal in the subsurface, HGT would be more likely to act within localized populations and would not contribute significantly to the broad patterns of vertical distribution that we see (Fig. 4).

\section{Drift}

Ecological drift refers to random changes in species relative abundances due to stochastic variables, such as random birth-death events within a population or unpredictable disturbances (Martiny et al. 2006, Vellend 2010, Nemergut et al. 2013). This concept is analogous to that of genetic drift in population genetics, whereby changes in gene frequencies in a population occur solely by chance (Chase \& Myers 2011). Although the factors influencing drift are largely unpredictable, they can still have significant effects on the composition of microbial communities. The relative importance of drift can be, in some cases, measured directly by comparing phylogenetic community composition data with randomized predictions or null model expectations (Stegen et al. 2012, 2013).
When applied in the terrestrial subsurface, this approach has shown that drift alone can govern up to $29 \%$ of microbial community turnover (Stegen et al. 2013). While significant, the effects of drift on community assembly in the terrestrial subsurface appear to be secondary to more deterministic processes, such as selection (Stegen et al. 2012).

Larger population sizes are expected to reduce the role of extinction through drift, as random changes in organism abundances are less likely to result in the removal of an entire population (Nemergut et al. 2013). Research in macro-ecology has shown that selective pressures and diversity can also influence drift (Chase \& Myers 2011). Specifically, the effects of drift are most significant when selection is weak and alpha diversity (the local species diversity) is low. Here, we find that diversity and richness are both highest within the uppermost meters of the sediment column (Fig. 3). As diversity and population sizes decrease with depth, drift could influence assembly patterns due to random extinction events. However, as the changes we see in the communities largely occur for larger populations, such as the Gammaproteobacteria (Fig. 5), the disappearances of these abundant taxa are less likely to be due to random extinction events.

\section{Selection}

The final mechanism of community assembly is the selection of individuals or populations due to fitness differences between taxa (Nemergut et al. 2013). Selection is imposed by abiotic and biotic pressures within the environment, the latter of which can be either antagonistic or synergistic (Stegen et al. 2012). The effects of selection typically manifest in the phylogenetic clustering of communities within similar environments. This is believed to be the result of ecological coherence within taxa, which suggests that phylogenetic units have ecological importance (Philippot et al. 2010). Ecological coherence has been demonstrated at high taxonomic levels, resulting in assemblages of microorganisms at the phyla or class level becoming clustered within similar environments (Philippot et al. 2009). Competition for resources can alter this picture, instead resulting in a pattern of phylogenetic overdispersion whereby species occupying a single habitat are more distantly related than expected by chance (Koeppel \& Wu 2014). The effects of selection are similar to those of diversification in that both produce phylogenetic or functional patterns in response to environmental parameters. How- 
ever, while diversification introduces new populations into a community, selection only affects the relative abundances of populations that are already present (Nemergut et al. 2013).

The global reduction in diversity and richness with depth seen in Fig. 3 is indicative of selection, as it suggests that certain populations disappear as they are buried deeper within the sediment column. These patterns mirror the energy-driven drop in microbial cell numbers with depth (Kallmeyer et al. 2012, Parkes et al. 2014, Jørgensen \& Marshall 2016), suggesting that the imposed energy limitations remove specific populations along with reducing the size of the total community. A similar relationship between microbial diversity and organic matter availability has been demonstrated in previous research, such as a study of Arctic deep-sea sediments which identified a positive response of bacterial OTU richness to increased phytodetrital input (Bienhold et al. 2012). A more recent analysis from 4 sites of the Integrated Ocean Drilling Program could directly correlate the depth-driven exponential decline in microbial richness with organic matter degradation rates, providing direct evidence that organic matter availability may drive the vertical drop in richness (Walsh et al. $2016 b)$. The productivity of the overlying water column has also been linked to sedimentary community composition, suggesting that different microbial taxa have varying fitness responses to energy limitations (Polymenakou et al. 2005, Bienhold et al. 2012). Varying adaptations to energy constraints may also explain the distributions of the most dominant populations seen here, which vary in relative abundance according to sediment depth (Fig. 5). The phylogenetic structuring of the surface environment differs markedly from the deep biosphere, and several prominent taxa are associated with the latter (Figs. $4 \& 5$, Teske 2006, 2013, Teske \& Sørensen 2008, Orcutt et al. 2011, Parkes et al. 2014). The groups of Archaea and Bacteria that become enriched within the deep subsurface are still present in higher sediment layers (Figs. 4 \& 5), suggesting that they are derived from a subset of the surface community. The majority of these dominant subsurface populations have been found to belong to a core subset of 'persister' microorganisms, whose relative abundances increase with sediment depth, irrespective of geochemical zonation (Starnawski et al. 2017). This relative increase in the abundance of specific taxa is indicative of selection and in sharp contrast to diversification and dispersal, both of which are responsible for bringing new populations into a community (Vellend 2010, Nemergut et al. 2013).
At the OTU level, community composition still changes systematically with depth, but sampling site also plays an important role in determining OTU composition particularly within the surface samples (Fig. 7A). Similarities in OTU composition within sites suggest that different geographic locations have endemic seed communities, which constrain the composition of the subsurface community below. This interpretation is supported by results from Zinger et al. (2014), which indicate that distance has a strong impact on community dissimilarity within surface sediments ( $\leq 10 \mathrm{cmbsf}$ ). Local communities of OTUs still show evidence of environmental filtering with depth, as demonstrated by the presence of persisting OTUs within each analyzed site (Fig. 7B-D). These OTUs make up a small subset of the total OTU richness but comprise a significant portion of the total microbial community. Patterns of persisting OTUs mirror the results by Starnawski et al. (2017), suggesting that environmental selection shapes subsurface communities on a global scale. OTUs classified as Atribacteria and Dehalococcoidia are among the most dominant persisters at all 3 analyzed sites. This reflects the results from the analyses of microbial classes with depth, reinforcing the expectation that selective processes are reflected at higher taxonomic levels (Philippot et al. 2009, 2010) despite variability in the OTU composition between sites.

Collectively, these observations suggest that the deep subsurface biosphere represents a highly selective habitat for microorganisms harboring favorable adaptations that may have emerged in other lowenergy environments, possibly independently of the sediment habitat. The transition into the deep subsurface is marked by a filtering of unadapted populations from the surface, as only a subset of persisting taxa survives and grows to dominate the subsurface community. Due to the close coupling between depth and energy depletion, it is likely that the ability to subsist within energy-limited environments would confer a selective advantage in the deep sediment and would be the primary force driving the patterns that are seen here.

\section{Traits for selective persistence}

As most subsurface microorganisms lack cultured representatives, it is difficult to link these phylogenetic patterns to an understanding of what traits confer a selective advantage in the energy-depleted deep biosphere. Broad analyses of taxonomic shifts are indicative of adaptation to low energy, most notably in terms 
of the relative increase in archaeal abundances with depth (Figs. 4 \& 5, Sørensen \& Teske 2006, Teske 2006, 2013, Teske \& Sørensen 2008, Orcutt et al. 2011, Parkes et al. 2014). Archaea are frequently found within extreme environments, and adaptation to chronic energy stress has even been proposed as the primary attribute distinguishing them from Bacteria (Valentine 2007). Still, what is the functional basis for their success in the deep biosphere, and how do select bacterial taxa also persist? A recent shift towards metagenomic and single-cell approaches has allowed a closer look into the physiological capabilities of these dominant uncultured organisms (Dodsworth et al. 2013, Lloyd et al. 2013, Nobu et al. 2016, Marshall et al. 2017, Starnawski et al. 2017). Atribacteria, for instance, are one of the most commonly described deepsediment phyla, reaching relative abundances of up to $48 \%$ in the deepest clay sediments in our metaanalysis and extending down to 500 mbsf (Fig. 5). Atribacteria have been proposed as heterotrophic anaerobes, with some lineages predicted to specialize in carbohydrate or fatty acid fermentation (Dodsworth et al. 2013, Carr et al. 2015, Nobu et al. 2016). Chloroflexi are also prominent members of the deep biosphere. Of these, the Dehalococcoidia are particularly abundant in the deeper samples, which is consistent with previous 16S rRNA diversity analyses (Ciobanu et al. 2014, Oni et al. 2015). Single-cell studies targeting Dehalococcoidia hint at a versatile metabolism, capable of fatty acid and organic compound oxidation as well as carbon dioxide fixation, sulfur cycling, and reductive dehalogenation (Kaster et al. 2014, Wasmund et al. 2014, 2016, Fullerton \& Moyer 2016). Among the archaeal groups, there is a dominance of Lokiarchaeota (MBG-B/DSAG), MG-I, Bathyarchaeota (MCG), and Methanomicrobia. The Bathyarchaeota are arguably the most widespread and abundant members of sediment communities, with relative abundances anywhere between 1 and 100\% and a very large phylogenetic diversity (Kubo et al. 2012, Lloyd et al. 2013, Fillol et al. 2016). Stable isotopic analyses of subsurface sediments off Peru have indicated that Bathyarchaeota may have a heterotrophic metabolism, growing by assimilation of fossil organic matter (Biddle et al. 2006). Additional approaches using single-cell genomics and metagenomics have suggested a role in the degradation of detrital proteins as well as acetogenesis (Lloyd et al. 2013, Lazar et al. 2016) and, more recently, the potential for methane metabolism in deep groundwater environments (Evans et al. 2015). Methanomicrobia are also dominant persisters that increase in relative abundance with depth. This class includes members of the anaero- bic methanotrophic (ANME) archaea, which are often enriched in the SMT zone in aggregates with sulfate reducers (Boetius et al. 2000). These analyses indicate that persisting taxonomic groups possess diverse metabolisms, with discoveries of new metabolic capabilities increasing dramatically in recent years (Lazar et al. 2015, Fullerton \& Moyer 2016, Nobu et al. 2016). Among these, there are many groups that are capable of growing fermentatively or by acetogenesis in deeper sediment layers. These metabolisms could confer an advantage in the sediment, as they would provide energy regardless of changing geochemistry. A similar theory was proposed by Lever et al. (2010), who suggested that the wide substrate spectrum available to acetogens may allow them to outcompete substrate specialists under extreme resource limitation. This expectation is also consistent with metagenomic data from Arctic Ocean sediments, which show that functional genes involved in fermentation greatly outnumber those responsible for terminal oxidation processes (Kirchman et al. 2014). Nonetheless, this is likely an oversimplification of the many metabolic niches present within the deep subsurface biosphere. Profiles of volatile fatty acids in marine sediments indicate that the concentrations of such fermentation end products are largely stable throughout much of the sediment column, suggesting that they are controlled by terminal mineralization processes throughout (Glombitza et al. 2015, C. Glombitza pers. comm.). Adaptations to energy limitations may also be unrelated to metabolic function, instead favoring physiological traits that allow cells to lower their BPR or increase their substrate uptake efficiency. Jørgensen \& Marshall (2016) review these and other possible adaptions to severe energy depletion. They suggest that cells in the deep subsurface biosphere may adapt by increasing ATP synthesis efficiency, either by reducing membrane permeability or by relying on alternative ions, namely sodium, for ATP production. Microorganisms that lack such adaptations may persist throughout the sediment column by sporulation, which allows them to switch to a dormant state when the energy flux drops below their BPR. This expectation is consistent with the present findings, which indicate a high relative abundance of Firmicutes in deeper sediment samples (Fig. 5). These sequences likely represent the dormant microorganisms themselves, as modern DNA extraction procedures target vegetative cells as well as endospores (Dineen et al. 2010). Previous sediment profiles have also shown that spores do have a dominant presence in the deep biosphere, with population sizes that are possibly as high as vegetative cells (Langerhuus et al. 2012, Lomstein et al. 2012). 
While promising, these analyses provide only a small insight into the range of microbial functions present within the sediment column. They are complicated by numerous factors, such as the potential for these organisms to alter their metabolic function in response to changing environmental parameters (Plugge et al. 2011). Functional differences among taxa may also represent selection pressures other than, or in addition to, energy limitation. The most notable of these is viral-induced cell death, which has been suggested to be a significant contributor to cellular mortality in the deep subsurface (Danovaro et al. 2008, Engelhardt et al. 2014, 2015, Jørgensen \& Marshall 2016). Resistance to viral lysis could mediate the selective survival of key taxa in the sediment column while also playing an important role in altering the subsurface environment. Both viral-induced and other forms of mortality are likely to contribute to the selective growth of surviving populations. However, at an estimated growth yield of $11 \%$, mortality can only account for a minor fraction of the organic carbon assimilated (Lomstein et al. 2012); microbial necromass formation thus only presents a small feedback loop, where unadapted populations that die off further increase the selective growth of persisting taxa.

\section{CONCLUSIONS AND PERSPECTIVES}

The information presented so far suggests that selection is the predominant force driving vertical community assembly in the sediment column. While diversification, dispersal, and drift could still theoretically impart changes, we expect that they are most influential within the surface environment, particularly within the bioturbation zone. This paints the picture of a relatively dynamic surface habitat, where mixing and bioirrigation produce heterogeneity, and the increased availability of electron donors and acceptors promotes community growth and turnover. As communities are buried below the bioturbation zone, they can only undergo limited adaptive evolution, leaving them subject to the gradient of selective pressures imposed by increasing depth within the sediment column. This expectation is consistent with previous research, which found that the biggest change in microbial community composition occurs between the surface environment and the SR zone below (Starnawski et al. 2017). Dissimilarities in OTU composition between sites suggest that different geographic locations have distinct seed communities, which constrain the composition of the subsurface community as they are buried over time (Fig. 7A). Despite this variability, each site appears to be subject to a similar gradient of environmental filtering with depth, leaving only a subset of (similar) persisting taxa to dominate the subsurface below (Fig. 7B-D). The environmental filtering seen in Figs. 4 \& 7 suggests that sediment depth and age are the major factors associated with selective pressures, as geochemical zonation would likely produce a more variable and stratified picture of taxonomic composition. However, due to the close association between microbial processes (Jørgensen 1982, Thomsen et al. 2001, Leloup et al. 2009, Holmkvist et al. 2011) and specific geochemical zones, it is feasible to assume that community changes still occur within these regions. These are likely changes that only affect a minor subset of the community (the terminal oxidizers) and do not contribute substantially to the broad patterns that we see. Environmental filtering has been previously implicated as a major driver of microbial community assembly in shallow aquifers, particularly with respect to deeper, fine-grained sediments (Stegen et al. 2013). Similar assembly processes are likely imposed within marine sediments and continuously shape the subsurface communities as they are buried over time. This conclusion is consistent with the previous hypothesis that microbes found in deep marine sediments exist as relics of past surface communities that have been buried over time (Inagaki et al. 2005, Teske 2013, Lever et al. 2015, Walsh et al. 2016a).

With the overarching theme of energy availability driving our understanding of these assembly processes, it is critical that we acknowledge current shortcomings in estimating in situ energy heterogeneity in the subsurface. Current estimates of percell metabolic rates and average biomass turnover times are derived from measurements of the bulk community, such as radiotracer techniques to estimate rates of SR (D'Hondt et al. 2002, Holmkvist et al. 2011, Hoehler \& Jørgensen 2013). Incubations with stable isotope-labeled substrates have demonstrated that the majority of cells are capable of metabolic activity under nutrient-rich conditions (Morono et al. 2011); however, virtually nothing is known regarding the variability in individual cell-specific activities in situ. If specialized populations are capable of preferentially utilizing the organic compounds present within the sediment while others remain dormant, our current activity estimates may be representative of only a small pool of metabolizing organisms. Any potential heterogeneity in activity can alter our understanding of the community dynamics we see here, as dormant populations represent an alternative means 
to avoid selective filtering with burial, as well as a seed community that may regain activity at variable depths within the sediment (Lennon \& Jones 2011). Significant discrepancies in cell-specific activities could also result in a few taxa with lower generation times and greater potential for diversification. To begin to address these questions of heterogeneity and the ways in which they may influence community assembly processes in the subsurface, we must expand on our current work to include analyses of the activities of single cells or individual taxa in situ.

Acknowledgements. This article is dedicated to Bo Barker Jørgensen on the occasion of his 70th birthday. We thank Birthe Zäncker, Hans Røy, Martin Polz, Alfred Spormann, Karen Lloyd, Mark A. Lever, Bo B. Jørgensen, Ian Marshall, and Clemens Glombitza for providing helpful discussions and data for this review. This work was supported by the Danish National Research Foundation (grant no. DNRF104) and an FP7 ERC Advanced Grant (no. 294200) to B. B. Jørgensen and grants from the Carlsberg Foundation, Julievon-Moellen Foundation, and Danish Agency for Science, Technology and Innovation to A.S.

\section{LITERATURE CITED}

Albalat R, Cañestro C (2016) Evolution by gene loss. Nat Rev Genet 17:379-391

Baas Becking LGM (1934) Geobiologie of inleiding tot de milieukunde. Van Stockum \& Zoon, The Hague

Bertics VJ, Ziebis W (2009) Biodiversity of benthic microbial communities in bioturbated coastal sediments is controlled by geochemical microniches. ISME J 3:1269-1285

Biddle JF, Lipp JS, Lever MA, Lloyd KG and others (2006) Heterotrophic Archaea dominate sedimentary subsurface ecosystems off Peru. Proc Natl Acad Sci USA 103: 3846-3851

Biddle JF, Fitz-Gibbon S, Schuster SC, Brenchley JE, House $\mathrm{CH}$ (2008) Metagenomic signatures of the Peru Margin subseafloor biosphere show a genetically distinct environment. Proc Natl Acad Sci USA 105(30):10583-10588

Bienhold C, Boetius A, Ramette A (2012) The energy-diversity relationship of complex bacterial communities in Arctic deep-sea sediments. ISME J 6:724-732

Blazejak A, Schippers A (2011) Real-time PCR quantification and diversity analysis of the functional genes aprA and $d s r A$ of sulfate-reducing prokaryotes in marine sediments of the Peru continental margin and the Black Sea. Front Microbiol 2:253

Boetius A, Ravenschlag K, Schubert CJ, Rickert D and others (2000) A marine microbial consortium apparently mediating anaerobic oxidation of methane. Nature 407:623-626

Boudreau BP (1998) Mean mixed depth of sediments: the wherefore and the why. Limnol Oceanogr 43:524-526

Brochier-Armanet C, Boussau B, Gribaldo S, Forterre P (2008) Mesophilic Crenarchaeota: proposal for a third archaeal phylum, the Thaumarchaeota. Nat Rev Microbiol 6:245-252

Canfield DE, Thamdrup B, Hansen JW (1993) The anaerobic degradation of organic matter in Danish coastal sediments: iron reduction, manganese reduction, and sulfate reduction. Geochim Cosmochim Acta 57:3867-3883

* Carr SA, Orcutt BN, Mandernack KW, Spear JR (2015) Abundant Atribacteria in deep marine sediment from the Adélie Basin, Antarctica. Front Microbiol 6:872

Chase JM, Myers JA (2011) Disentangling the importance of ecological niches from stochastic processes across scales. Philos Trans R Soc Lond B 366:2351-2363

Ciobanu MC, Burgaud G, Dufresne A, Breuker A and others (2014) Microorganisms persist at record depths in the subseafloor of the Canterbury Basin. ISME J 8:1370-1380

Wanovaro R, Anno AD, Corinaldesi C, Magagnini M, Noble R, Tamburini C, Weinbauer M (2008) Major viral impact on the functioning of benthic deep-sea ecosystems. Nature 454:1084-1087

DeLong EF (1992) Archaea in coastal marine environments. Proc Natl Acad Sci USA 89:5685-5689

№vereux R, Mosher JJ, Vishnivetskaya TA, Brown SD, Beddick DL Jr, Yates DF, Palumbo AV (2015) Changes in northern Gulf of Mexico sediment bacterial and archaeal communities exposed to hypoxia. Geobiology 13:478-493

de Wit R, Bouvier T (2006) 'Everything is everywhere, but, the environment selects'; what did Baas Becking and Beijerinck really say? Environ Microbiol 8:755-758

D'Hondt S, Rutherford S, Spivack AJ (2002) Metabolic activity of subsurface life in deep-sea sediments. Science 295: 2067-2070

* Dineen SM, Iv RA, Anders DL, Robertson JM (2010) An evaluation of commercial DNA extraction kits for the isolation of bacterial spore DNA from soil. J Appl Microbiol 109:1886-1896

Dodsworth JA, Blainey PC, Murugapiran SK, Swingley WD and others (2013) Single-cell and metagenomic analyses indicate a fermentative and saccharolytic lifestyle for members of the OP9 lineage. Nat Commun 4:1854

* Durbin AM, Teske A (2012) Archaea in organic-lean and organic-rich marine subsurface sediments: an environmental gradient reflected in distinct phylogenetic lineages. Front Microbiol 3:168

* Dyksma S, Bischof K, Fuchs BM, Hoffmann K and others (2016) Ubiquitous Gammaproteobacteria dominate dark carbon fixation in coastal sediments. ISME J 10: 1939-1953

*Edgar RC (2013) UPARSE: highly accurate OTU sequences from microbial amplicon reads. Nat Methods 10:996-998

* Edgar RC, Haas BJ, Clemente JC, Quince C, Knight R (2011) UCHIME improves sensitivity and speed of chimera detection. Bioinformatics 27:2194-2200

Engelhardt T, Kallmeyer J, Cypionka H, Engelen B (2014) High virus-to-cell ratios indicate ongoing production of viruses in deep subsurface sediments. ISME J 8:1503-1509

Engelhardt T, Orsi WD, Jørgensen BB (2015) Viral activities and life cycles in deep subseafloor sediments. Environ Microbiol Rep 7:868-873

Evans PN, Parks DH, Chadwick GL, Robbins SJ, Orphan VJ, Golding SD, Tyson GW (2015) Methane metabolism in the archaeal phylum Bathyarchaeota revealed by genomecentric metagenomics. Science 350:434-438

Fenchel T (2002) Microbial behavior in a heterogeneous world. Science 296:1068-1071

Fenchel T (2008) Motility of bacteria in sediments. Aquat Microb Ecol 51:23-30

Fillol M, Auguet JC, Casamayor EO, Borrego CM (2016) Insights in the ecology and evolutionary history of the Miscellaneous Crenarchaeotic Group lineage. ISME J 10:665-677 
Froehlich PN, Klinkhammer GP, Bender ML, Luedtke NA and others (1979) Early oxidation of organic matter in pelagic sediments of the eastern equatorial Atlantic: suboxic diagenesis. Geochim Cosmochim Acta 43:1075-1090

Fullerton H, Moyer CL (2016) Comparative single-cell genomics of Chloroflexi from the Okinawa Trough deep subsurface biosphere. Appl Environ Microbiol 82:3000-3008

* Gilbert JA, Steele JA, Caporaso JG, Steinbrück L and others (2012) Defining seasonal marine microbial community dynamics. ISME J 6:298-308

Giovannoni SJ (1990) Genetic diversity in Sargasso Sea bacterioplankton. Nature 345:60-63

*Glombitza C, Jaussi M, Røy H, Seidenkrantz M, Lomstein BA, Jørgensen BB (2015) Formate, acetate, and propionate as substrates for sulfate reduction in sub-arctic sediments of southwest Greenland. Front Microbiol 6:846

* Hamdan LJ, Coffin RB, Sikaroodi M, Greinert J, Treude T, Gillevet PM (2013) Ocean currents shape the microbiome of Arctic marine sediments. ISME J 7:685-696

Hedges JI, Keil RG (1995) Sedimentary organic matter preservation: an assessment and speculative synthesis. Mar Chem 49:81-115

Hewson I, Jacobson-Meyers ME, Fuhrman JA (2007) Diversity and biogeography of bacterial assemblages in surface sediments across the San Pedro Basin, southern California borderlands. Environ Microbiol 9:923-933

* Hill TCJ, Walsh KA, Harris JA, Moffett BF (2003) Using ecological diversity measures with bacterial communities. FEMS Microbiol Ecol 43:1-11

*Hoehler TM, Jørgensen BB (2013) Microbial life under extreme energy limitation. Nat Rev Microbiol 11:83-94

* Holmkvist L, Ferdelman TG, Jørgensen BB (2011) A cryptic sulfur cycle driven by iron in the methane zone of marine sediment (Aarhus Bay, Denmark). Geochim Cosmochim Acta 75:3581-3599

Hugenholtz P, Pitulle C, Hershberger KL, Pace NR (1998) Novel division level bacterial diversity in a Yellowstone hot spring. J Bacteriol 180:366-376

Hughes JB, Hellmann JJ, Ricketts TH, Bohannan BJM (2001) Counting the uncountable: statistical approaches to estimating microbial diversity. Appl Environ Microbiol 67: 4399-4406

Inagaki F, Suzuki M, Takai K, Oida H and others (2003) Microbial communities associated with geological horizons in coastal subseafloor sediments from the Sea of Okhotsk. Appl Environ Microbiol 69:7224-7235

Inagaki F, Okada H, Tsapin AI, Nealson KH (2005) Microbial survival: the paleome: a sedimentary genetic record of past microbial communities. Astrobiology 5:141-153

* Inagaki F, Nunoura T, Nakagawa S, Teske A and others (2006) Biogeographical distribution and diversity of microbes in methane hydrate-bearing deep marine sediments on the Pacific Ocean Margin. Proc Natl Acad Sci USA 103:2815-2820

Inagaki F, Kubo Y, Bowles MW, Heuer VB and others (2015) Exploring deep microbial life in coal-bearing sediment down to $\sim 2.5 \mathrm{~km}$ below the ocean floor. Science 349 : $420-424$

Jørgensen BB (1982) Mineralization of organic matter in the sea bed - the role of sulphate reduction. Nature 296: 643-645

Jørgensen BB, Marshall IPG (2016) Slow microbial life in the seabed. Annu Rev Mar Sci 8:311-332

Jorgensen SL, Hannisdal B, Lanzén A, Baumberger T and others (2012) Correlating microbial community profiles with geochemical data in highly stratified sediments from the Arctic Mid-Ocean Ridge. Proc Natl Acad Sci USA 109:E2846-E2855

Kallmeyer J, Pockalny R, Ram R, Smith DC, D'Hondt S (2012) Global distribution of microbial abundance and biomass in subseafloor sediment. Proc Natl Acad Sci USA 109: 16213-16216

K Kaster AK, Mayer-Blackwell K, Pasarelli B, Spormann AM (2014) Single cell genomic study of Dehalococcoidetes species from deep-sea sediments of the Peruvian Margin. ISME J 8:1831-1842

Kawai M, Futagami T, Toyoda A, Takaki Y and others (2014) High frequency of phylogenetically diverse reductive dehalogenase-homologous genes in deep subseafloor sedimentary metagenomes. Front Microbiol 5:80

Kempes CP, van Bodegom PM, Wolpert D, Libby E, Amend J, Hoehler T (2017) Drivers of bacterial maintenance and minimal energy requirements. Front Microbiol 8:31

K Kirchman DL, Hanson TE, Cottrell MT, Hamdan LJ (2014) Metagenomic analysis of organic matter degradation in methane-rich Arctic Ocean sediments. Limnol Oceanogr 59:548-559

Koeppel AF, Wu M (2014) Species matter: the role of competition in the assembly of congeneric bacteria. ISME J 8: $531-540$

Kristensen E (2001) Impact of polychaetes (Nereis spp. and Arenicola marina) on carbon biogeochemistry in coastal marine sediments. Geochem Trans 2:92

Kristensen E, Penha-Lopes G, Delefosse M, Valdemarsen T, Quintana CO, Banta GT (2012) What is bioturbation? The need for a precise definition for fauna in aquatic sciences. Mar Ecol Prog Ser 446:285-302

Kubo K, Lloyd KG, Biddle JF, Amann R, Teske A, Knittel K (2012) Archaea of the Miscellaneous Crenarchaeotal Group are abundant, diverse and widespread in marine sediments. ISME J 6:1949-1965

次Langerhuus AT, Røy H, Lever MA, Morono Y, Inagaki F, Jørgensen BB, Lomstein BA (2012) Endospore abundance and D:L-amino acid modeling of bacterial turnover in holocene marine sediment (Aarhus Bay). Geochim Cosmochim Acta 99:87-99

* Lazar CS, Baker BJ, Seitz K, Hyde AS, Dick GJ, Hinrichs K, Teske AP (2016) Genomic evidence for distinct carbon substrate preferences and ecological niches of Bathyarchaeota in estuarine sediments. Environ Microbiol 18: 1200-1211

Keloup J, Loy A, Knab NJ, Borowski C, Wagner M, Jørgensen BB (2007) Diversity and abundance of sulfatereducing microorganisms in the sulfate and methane zones of a marine sediment, Black Sea. Environ Microbiol 9:131-142

Keloup J, Fossing H, Kohls K, Holmkvist L, Borowski C, Jørgensen BB (2009) Sulfate-reducing bacteria in marine sediment (Aarhus Bay, Denmark): abundance and diversity related to geochemical zonation. Environ Microbiol 11:1278-1291

Kennon JT, Jones SE (2011) Microbial seed banks: the ecological and evolutionary implications of dormancy. Nat Rev Microbiol 9:119-130

* Lever MA (2013) Functional gene surveys from ocean drilling expeditions - a review and perspective. FEMS Microbiol Ecol 84:1-23

Lever MA, Heuer VB, Morono Y, Masui N and others (2010) Acetogenesis in deep subseafloor sediments of the Juan de Fuca Ridge flank: a synthesis of geochemical, thermo- 
dynamic, and gene-based evidence. Geomicrobiol J 27: 183-211

Lever MA, Rogers KL, Lloyd KG, Overmann J and others (2015) Life under extreme energy limitation: a synthesis of laboratory- and field-based investigations. FEMS Microbiol Rev 39:688-728

Li H, Yu Y, Luo W, Zeng Y, Chen B (2009) Bacterial diversity in surface sediments from the Pacific Arctic Ocean. Extremophiles 13:233-246

Lloyd KG, Schreiber L, Petersen DG, Kjeldsen KU and others (2013) Predominant archaea in marine sediments degrade detrital proteins. Nature 496:215-218

Lomstein BA, Langerhuus AT, D'Hondt S, Jørgensen BB, Spivack AJ (2012) Endospore abundance, microbial growth and necromass turnover in deep sub-seafloor sediment. Nature 484:101-104

Loy A, Küsel K, Lehner A, Drake HL, Wagner M (2004) Microarray and functional gene analyses of sulfatereducing prokaryotes in low-sulfate, acidic fens reveal cooccurrence of recognized genera and novel lineages. Appl Environ Microbiol 70:6998-7009

Mahmoudi N, Robeson MS, Castro HF, Fortney JL and others (2015) Microbial community composition and diversity in Caspian Sea sediments. FEMS Microbiol Ecol 91: $1-11$

Marshall IPG, Starnawski P, Cupit C, Cáceres EF, Ettema TJG, Schramm A, Kjeldsen KU (2017) The novel bacterial phylum Calditrichaeota is diverse, widespread and abundant in marine sediments and has the capacity to degrade detrital proteins. Environ Microbiol Rep, doi: 10.1111/1758-2229.12544

Martiny JBH, Bohannan BJM, Brown JH, Colwell RK and others (2006) Microbial biogeography: putting microorganisms on the map. Nat Rev Microbiol 4:102-112

Meng J, Xu J, Qin D, He Y, Xiao X, Wang F (2014) Genetic and functional properties of uncultivated MCG archaea assessed by metagenome and gene expression analyses. ISME J 8:650-659

Meyer-Reil LA (1994) Microbial life in sedimentary biofilms - the challenge to microbial ecologists. Mar Ecol Prog Ser 112:303-311

Meysman FJR, Middelburg JJ, Heip CHR (2006) Bioturbation: a fresh look at Darwin's last idea. Trends Ecol Evol 21:688-695

Middelburg JJ (1989) A simple rate model for organic matter decomposition in marine sediments. Geochim Cosmochim Acta 53:1577-1581

Middelburg JJ, Vlug T, van der Nat FJWA (1993) Organic matter mineralization in marine systems. Glob Planet Chang 8:47-58

Mittelbach GG, Schemske DW (2015) Ecological and evolutionary perspectives on community assembly. Trends Ecol Evol 30:241-247

Morono Y, Terada T, Nishizawa M, Ito M and others (2011) Carbon and nitrogen assimilation in deep subseafloor microbial cells. Proc Natl Acad Sci USA 108:18295-18300

Morris RM, Rappé MS, Connon SA, Vergin KL, Siebold WA, Carlson CA, Giovannoni SJ (2002) SAR11 clade dominates ocean surface bacterioplankton communities. Nature 420:806-810

Nemergut DR, Schmidt SK, Fukami T, Neill SPO and others (2013) Patterns and processes of microbial community assembly. Microbiol Mol Biol Rev 77:342-356

Nobu MK, Dodsworth JA, Murugapiran SK, Rinke C and others (2016) Phylogeny and physiology of candidate phylum 'Atribacteria' (OP9/JS1) inferred from cultivation-independent genomics. ISME J 10:273-286

“ Oni OE, Schmidt F, Miyatake T, Kasten S, Witt M, Hinrichs KU, Friedrich MW (2015) Microbial communities and organic matter composition in surface and subsurface sediments of the Helgoland mud area, North Sea. Front Microbiol 6:1290

* Orcutt BN, Sylvan JB, Knab NJ, Edwards KJ (2011) Microbial ecology of the dark ocean above, at, and below the seafloor. Microbiol Mol Biol Rev 75:361-422

* Parkes RJ, Cragg B, Roussel E, Webster G, Weightman A, Sass H (2014) A review of prokaryotic populations and processes in sub-seafloor sediments, including biosphere:geosphere interactions. Mar Geol 352:409-425

* Philippot L, Bru D, Saby NPA, uhel J, Arrouays D, Šimek M, Hallin S (2009) Spatial patterns of bacterial taxa in nature reflect ecological traits of deep branches of the 16S rRNA bacterial tree. Environ Microbiol 11:3096-3104

*Philippot L, Andersson SGE, Battin TJ, Prosser JI, Schimel JP, Whitman WB, Hallin S (2010) The ecological coherence of high bacterial taxonomic ranks. Nat Rev Microbiol 8:523-529

* Plugge CM, Zhang W, Scholten JCM, Stams AJM (2011) Metabolic flexibility of sulfate-reducing bacteria. Front Microbiol 2:81

Polymenakou PN, Bertilsson S, Tselepides A, Stephanou EG (2005) Links between geographic location, environmental factors, and microbial community composition in sediments of the eastern Mediterranean Sea. Microb Ecol 49:367-378

*Prozorov AA (2001) Recombinational rearrangements in bacterial genome and bacterial adaptation to the environment. Microbiology 70:501-511

* Quaiser A, Zivanovic Y, Moreira D, López-García P (2011) Comparative metagenomics of bathypelagic plankton and bottom sediment from the Sea of Marmara. ISME J 5: 285-304

Quast C, Pruesse E, Yilmaz P, Gerken J and others (2013) The SILVA ribosomal RNA gene database project: improved data processing and web-based tools. Nucleic Acids Res 41:D590-D596

* Reed DW, Fujita Y, Delwiche ME, Blackwelder DB, Sheridan PP, Uchida T, Colwell FS (2002) Microbial communities from methane hydrate-bearing deep marine sediments in a forearc basin. Appl Environ Microbiol 68: 3759-3770

* Reichardt W (1988) Impact of bioturbation by Arenicola marina on microbiological parameters in intertidal sediments. Mar Ecol Prog Ser 44:149-158

* Reise K (2002) Sediment mediated species interactions in coastal waters. J Sea Res 48:127-141

Røy H, Kallmeyer J, Adhikari RR, Pockalny R, Jorgensen BB, D'Hondt S (2012) Aerobic microbial respiration in 86million-year-old deep-sea red clay. Science 336:922-925

* Salter SJ, Cox MJ, Turek EM, Calus ST and others (2014) Reagent and laboratory contamination can critically impact sequence-based microbiome analyses. BMC Biol 12:87

* Schippers A, Neretin LN, Kallmeyer J, Ferdelman TG, Cragg BA, Parkes RJ, Jørgensen BB (2005) Prokaryotic cells of the deep sub-seafloor biosphere identified as living bacteria. Nature 433:861-864

Schippers A, Kock D, Höft C, Köweker G, Siegert M (2012) Quantification of microbial communities in subsurface marine sediments of the Black Sea and off Namibia. Front Microbiol 3:16 
Schloss PD, Westcott SL, Ryabin T, Hall JR and others (2009) Introducing mothur: open-source, platform-independent, community-supported software for describing and comparing microbial communities. Appl Environ Microbiol 75:7537-7541

Sørensen KB, Teske A (2006) Stratified communities of active Archaea in deep marine subsurface sediments. Appl Environ Microbiol 72:4596-4603

Spang A, Saw JH, Jørgensen SL, Zaremba-Niedzwiedzka K and others (2015) Complex archaea that bridge the gap between prokaryotes and eukaryotes. Nature 521: 173-179

Starnawski P, Batallion T, Ettema TJG, Jochum LM and others (2017) Microbial community assembly and evolution in subseafloor sediment. Proc Natl Acad Sci USA 114: 2940-2945

Stegen JC, Lin X, Konopka AE, Fredrickson JK (2012) Stochastic and deterministic assembly processes in subsurface microbial communities. ISME J 6:1653-1664

Stegen JC, Lin X, Fredrickson JK, Chen X and others (2013) Quantifying community assembly processes and identifying features that impose them. ISME J 7:2069-2079

Taylor JR, Stocker R (2012) Trade-offs of chemotactic foraging in turbulent water. Science 338:675-679

Teske AP (2006) Microbial communities of deep marine subsurface sediments: molecular and cultivation surveys. Geomicrobiol J 23:357-368

Teske A (2013) Marine deep sediment microbial communities. In: Rosenberg E, DeLong EF, Lory S, Stackebrandt E, Thompson F (eds) The prokaryotes. Springer, Berlin, p 123-138

Teske A, Sørensen KB (2008) Uncultured archaea in deep marine subsurface sediments: Have we caught them all? ISME J 2:3-18

* Thamdrup B, Fossing H, Jorgensen BB (1994) Manganese, iron, and sulfur cycling in a coastal marine sediment, Aarhus Bay, Denmark. Geochim Cosmochim Acta 58: 5115-5129

Thomsen TR, Finster K, Ramsing NB (2001) Biogeochemical and molecular signatures of anaerobic methane oxidation in a marine sediment. Appl Environ Microbiol 67: 1646-1656

Valentine DL (2007) Adaptations to energy stress dictate the ecology and evolution of the Archaea. Nat Rev Microbiol 5:316-232

Vellend M (2010) Conceptual synthesis in community ecology.

Editorial responsibility: Eva Lindström,

Uppsala, Sweden
Q Rev Biol 85:183-206

Vetriani C, Jannasch HW, MacGregor BJ, Stahl DA, Reysenbach A (1999) Population structure and phylogenetic characterization of marine benthic archaea in deep-sea sediments. Appl Environ Microbiol 65(10):4375-4384

Walsh EA, Kirkpatrick JB, Rutherford SD, Smith DC, Sogin M, D'Hondt S (2016a) Bacterial diversity and community composition from seasurface to subseafloor. ISME J 10: 979-989

*Walsh EA, Kirkpatrick JB, Pockalny R, Sauvage J and others (2016b) Relationship of bacterial richness to organic degradation rate and sediment age in subseafloor sediment. Appl Environ Microbiol 82:4994-4999

Wasmund K, Schreiber L, Lloyd KG, Petersen DG and others (2014) Genome sequencing of a single cell of the widely distributed marine subsurface Dehalococcoidia, phylum Chloroflexi. ISME J 8:383-397

Wasmund K, Cooper M, Schreiber L, Lloyd KG and others (2016) Single-cell genome and group-specific $d s r A B$ sequencing implicate marine members of the class Dehalococcoidia (phylum Chloroflexi) in sulfur cycling. MBio 7 : $1-15$

Webster G, Parkes RJ, Fry JC, Weightman AJ (2004) Widespread occurrence of a novel division of bacteria identified by $16 \mathrm{~S}$ rRNA gene sequences originally found in deep marine sediments. Appl Environ Microbiol 70:5708-5713

*Weller C, Wu M (2015) A generation-time effect on the rate of molecular evolution in bacteria. Evolution 69:643-652

Whittaker RH (1972) Evolution and measurement of species diversity. Taxon 21:213-251

Wiedenbeck J, Cohan FM (2011) Origins of bacterial diversity through horizontal genetic transfer and adaptation to new ecological niches. FEMS Microbiol Rev 35:957-976

Zäncker B (2015) Persistence and dispersal of microbial populations in subsurface marine sediments. MSc dissertation, University of Bremen, Bremen

Z Zaremba-Niedzwiedzka K, Caceres E, Saw J, Bäckström D and others (2017) Asgard archaea illuminate the origin of eukaryotic cellular complexity. Nature 541:353-358

Zinger L, Amaral-Zettler LA, Fuhrman JA, Horner-Devine MC and others (2011) Global patterns of bacterial betadiversity in seafloor and seawater ecosystems. PLOS ONE 6:e24570

Zinger L, Boetius A, Ramette A (2014) Bacterial taxa-area and distance-decay relationships in marine environments. Mol Ecol 23:954-964

Submitted: October 12, 2016; Accepted: March 20, 2017

Proofs received from author(s): May 18, 2017 